\title{
A Supplementary Clear-Sky Snow and Ice Recognition Technique for CERES Level 2 Products
}

\author{
Alexander Radkevich, Konstantin Khlopenkov, and David Rutan \\ Science Systems and Applications, Inc., Hampton, Virginia \\ SEIJI KATO \\ NASA Langley Research Center, Hampton, Virginia
}

(Manuscript received 7 May 2012, in final form 7 November 2012)

\begin{abstract}
Identification of clear-sky snow and ice is an important step in the production of cryosphere radiation budget products, which are used in the derivation of long-term data series for climate research. In this paper, a new method of clear-sky snow/ice identification for Moderate Resolution Imaging Spectroradiometer (MODIS) is presented. The algorithm's goal is to enhance the identification of snow and ice within the Clouds and the Earth's Radiant Energy System (CERES) data after application of the standard CERES scene identification scheme. The input of the algorithm uses spectral radiances from five MODIS bands and surface skin temperature available in the CERES Single Scanner Footprint (SSF) product. The algorithm produces a cryosphere rating from an aggregated test: a higher rating corresponds to a more certain identification of the clear-sky snow/ice-covered scene. Empirical analysis of regions of interest representing distinctive targets such as snow, ice, ice and water clouds, open waters, and snow-free land selected from a number of MODIS images shows that the cryosphere rating of snow/ice targets falls into $95 \%$ confidence intervals lying above the same confidence intervals of all other targets. This enables recognition of clear-sky cryosphere by using a single threshold applied to the rating, which makes this technique different from traditional branching techniques based on multiple thresholds. Limited tests show that the established threshold clearly separates the cryosphere rating values computed for the cryosphere from those computed for noncryosphere scenes, whereas individual tests applied consequently cannot reliably identify the cryosphere for complex scenes.
\end{abstract}

\section{Introduction}

Clouds and the Earth's Radiant Energy System (CERES) instruments are currently flying on board the National Aeronautics and Space Administration's (NASA) Terra and Aqua Earth Observing System (EOS) spacecrafts (two instruments on each) and Suomi National Polar-Orbiting Partnership (NPP) observatory. CERES sensors measure radiances reflected and emitted by the earth in three broadband ranges: shortwave (SW) $0.3-5 \mu \mathrm{m}$, atmospheric window-8-12 $\mu \mathrm{m}$, and total0.3-100 $\mu \mathrm{m}$ (Wielicki et al. 1996).

The CERES Cloud Working Group (CWG) developed a set of cloud detection and retrieval algorithms with their results released as part of the CERES Single

Corresponding author address: Alexander Radkevich, SSAI, 1 Enterprise Parkway, Hampton, VA 23666.

E-mail: alexander.radkevich@nasa.gov
Scanner Footprint (SSF) product (Caldwell et al. 2008; Minnis et al. 2003, 2004, 2008, 2011). This product contains a scene identification (including clear area percent coverage, and snow and ice percent coverage), retrieved cloud properties, CERES broadband radiances, and Moderate Resolution Imaging Spectroradiometer (MODIS) radiances within the CERES field of view (FOV). In the SSF, MODIS imager pixels $(\sim 1 \mathrm{~km})$ are collocated within the larger CERES footprint $(\sim 20 \mathrm{~km})$ and weighted by the energy distribution of the CERES instrument (point spread function) over the full CERES FOV and its clear-sky portion. Along with cloud properties, such as optical depth, emissivity, cloud top and base, the SSF includes some ancillary data, such as the viewed surface emissivity and scene type. Atmospheric conditions, from which some cloud properties are determined, such as temperature, pressure, and humidity profiles, are based on the Goddard Earth Observing System reanalyses, version 4 (GEOS-4) (Bloom et al. 2005), until 
the end of 2007, and GEOS-5 thereafter (Rienecker et al. 2008).

Top-of-atmosphere (TOA) irradiances are derived by application of scene-dependent angular distribution models (ADMs) (Loeb et al. 2005) to measured TOA radiances. ADMs are derived from CERES data acquired in CERES rotating azimuth plane scan mode to establish the bidirectional reflectance distribution function on the scale of $\sim 30-\mathrm{km}$ broadband footprints. The uncertainty of ADM-derived TOA shortwave irradiance is about $5 \%$ (Loeb et al. 2005, 2007) and decreases when the irradiances derived from a wide range of viewing geometries are averaged.

Calculation of irradiance through the atmosphere is performed by CERES Surface and Atmosphere Radiation Budget (SARB) working group (Charlock et al. 1997, 2006). This is accomplished by means of a fast radiative transfer code originally developed by Fu and Liou (1993) and subsequently modified by the SARB team (Rose and Charlock 2002; Kato et al. 2005). The baseline data product for the SARB subsystem is the clouds and radiative swath (CRS). Along with CERES TOA irradiances and cloud analyses, CRS records include column irradiances at four atmospheric levels and the surface. These irradiances are a subset of the radiative transfer calculations, which are executed at more vertical levels.

CERES CRS processing for clear-sky footprints invokes a parameterized version of the Langley Fu-Liou radiative transfer model to derive the broadband surface albedos consistent with CERES-observed TOA irradiances. The model described in Rutan et al. (2009) is also used in a preprocessor that generates a first-guess "history map" of surface albedo, globally, for each month to be used in cloudy-sky model calculations. To create these maps, the parameterization is run for each month for $100 \%$ clear-sky CERES footprints collected into a $16^{\circ}$ equal angle grid over the globe. The values within each grid box are then examined and weighted as a function of solar zenith, viewing zenith, and aerosol optical depth to arrive at an optimal surface albedo for that grid box for that month. More weight is given to more optimal viewing conditions, such as higher sun and lower aerosol loading, where less optimal viewing conditions receive less weight.

Rutan et al. (2009) showed that the surface albedo products derived from MODIS (Schaaf et al. 2002) and CERES data over snow-free land are in good agreement on the scale of the CERES footprint. Our comparison of these two products over the cryosphere revealed, however, some discrepancies. Careful examination of these discrepancies showed that most of them are related to problems with scene identification. Thus, some correction to the clear-sky cryosphere identification is required in order to improve the quality of the CERES surface albedo product. Moreover, in polar regions, the number of footprints that are entirely cloud free is limited because of significant cloud cover (more than $70 \%$ ) in the Arctic during summertime (e.g., Kato et al. 2006). To increase the number of cloud-free events used to build the surface albedo history map, we propose to use the clear portion of the partly cloudy footprints in order to increase the number of retrievals for the surface albedo. To utilize partly cloudy footprints and to build an accurate surface albedo history map for the cryosphere, the cloud-free portion of a footprint has to be identified properly, so as to avoid, for example, cloud contamination affecting the retrieved surface albedo.

Once the cloud-free portion of a CERES footprint is identified, the mean MODIS radiance over the cloudfree portion is converted to a broadband radiance using a narrowband to broadband model. Conversion coefficients are derived from regressions between MODIS and CERES radiances over 100\% clear-sky FOVs and then applied to MODIS radiances over clear portions of cloudy FOVs. CERES ADMs are then applied to the resulting broadband radiances. This new approach uses the advantages from both the CERES algorithm and the MODIS high spatial resolution, thus enabling the surface albedo retrievals over areas with persistent cloudiness.

This paper describes an algorithm that helps the decision as to whether a CERES FOV is over clear-sky snow/ice or not. In the CERES data processing, this algorithm is now used to confirm (or refute) the clearsky snow/ice identification of a FOV provided by the standard CERES cloud detection algorithm. In particular, the algorithm evaluates the cloud-free portion of a CERES footprint identified by the edition 2 CERES (Ed2) cloud algorithm (Minnis et al. 2011) and determines whether the footprint should be included in building the surface albedo history map. Thus, two requirements in developing such an algorithm are 1) the algorithm has to provide an improvement to the CERES cloud algorithm and 2) the algorithm should use only inputs available in the CERES SSF product. Even though the algorithm is used in the CERES data processing as a compliment to the $\mathrm{Ed} 2$ cloud algorithm, the approach used in our algorithm is independent of any output of the CERES cloud algorithm. The approach used by our algorithm highlights spectral signatures of frozen water on the ground, and therefore it can be used for snow/ice identification regardless of CERES data processing.

The algorithm outlined in this paper differs from existing clear-sky cryosphere detection algorithms based on MODIS observations in two ways. First, it is 
not based on a cascading threshold approach and, second, it does not rely on a standalone cloud mask. The MODIS algorithm consists of two parts designed to produce an instantaneous snow map at 500-m resolution (MOD10_L2) and a sea ice map at 1-km resolution (MOD29). Both of those branches explicitly use the MODIS cloud mask that, in turn, employs 14 out of 36 MODIS bands. Detailed discussion of the MODIS snow and ice algorithms is given in Hall et al. (2001, 2002, 2004) and references therein. The CERES cryosphere detection algorithm is an integral part of the cloud and snow detection algorithm. Unlike MODIS cloud detection, the CERES cloud detection and scene identification algorithm was developed to utilize as few bands as possible (Minnis et al. 2011). Currently, it employs a set of cascading thresholds tests. The general philosophy of the CERES algorithm is to detect clouds first and then classify clear pixels. Subclassification of clear pixels includes the snow/ice class (Trepte et al. 2002; Minnis et al. 2008).

\section{Statement of the problem}

The CERES scene identification algorithm includes snow and ice detection utilizing a set of cascading thresholds tests to identify MODIS pixels as cloudy, clear, and clear snow/ice contaminated. The algorithm works well for the majority of CERES FOVs. However, some problems remain that affect subsequent CERES products such as the surface albedo used in CRS radiative transfer calculations. There are three possible situations with erroneous cryosphere scene identification: 1) the clear-sky snow/ice scene is recognized as cloudy (at least partly cloudy),2) the scene is recognized as clearsky cryosphere but snow or ice percent coverage is not identified correctly, and 3) a cloudy scene is recognized as clear snow/ice.

Figure 1 presents an example of an erroneously identified scene. It shows part of a MODIS image acquired over the Great Plains on 8 January 2004. The color scheme of the figure allows for easy recognition of frozen water: snow, ice, and ice clouds are bluish due to relatively low reflectance in band 6 over these targets. Water clouds are white and possibly slightly reddish with this color scheme; clear land can be of many colors, such as brown, red, orange, and green, depending on the type of vegetation; water bodies are usually very dark, almost black. The light gray circle encloses a region of interest (ROI) cocentered with a CERES FOV acquired at $17 \mathrm{~h}$, $37 \mathrm{~min}, 6.368 \mathrm{~s}$ UTC. The ROI has a diameter of $291-\mathrm{km}$ MODIS pixels and includes 632 pixels. We will consider the ROI as a model of the FOV. The FOV was identified as $100 \%$ cloud free and $100 \%$ snow covered. One can see

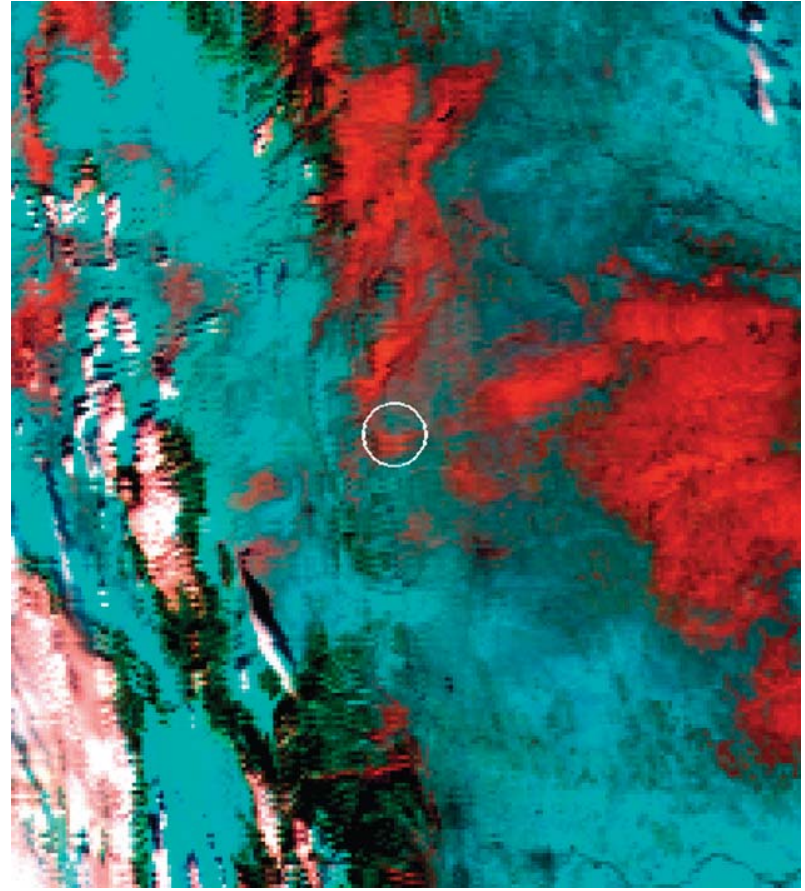

FIG. 1. A part of MODIS image MOD021km.A2004008.1735 acquired on 8 Jan 2004 over the Great Plains. Color scheme: reflectances in MODIS bands 6, 2, and 1 represent red, green and blue, respectively. Light gray circle is cocentered with CERES FOV acquired on the same day at $17 \mathrm{~h}, 37 \mathrm{~min}, 6.368 \mathrm{~s}$ UTC. The diameter of the circle is 29 MODIS 1-km pixels, that is about the size of the FOV.

from Fig. 1 that the clear-sky identification is correct, but that the snow percent coverage is overestimated as this FOV is only partly snow covered. We shall return to this FOV after the introduction of the cryosphere rating in section 5 .

Complete reprocessing with implementation of a new scene identification and cloud detection algorithm is required in order to fix problems of the first kind. Errors of scene identification of the second and third kinds can be filtered out by applying additional criteria after scene identification by the CERES cloud algorithm. Such a check should confirm results of the standard CERES scene identification over the cryosphere. Taking into account the large amount of data to be processed (CERES SSF files contain $\sim 10^{5}$ FOVs per hour), the algorithm should be solely based on information from standard SSF records. Another requirement for the algorithm is that it cannot assume that the CERES cloud detection and scene identification is correct. Our special area of interest is the enhancement of CERES shortwave products, including surface albedo over the cryosphere. For this reason we consider only daytime snow and ice identification. We also limit this algorithm to data from the MODIS Terra sensor. 
The standard SSF record contains MODIS TOA radiance values, one averaged over the whole CERES FOV and another over its clear-sky portion. These mean radiances were weighted by the CERES point spread function. Every daytime FOV record contains averaged radiances in the MODIS bands 1, 2, 6, 20, and 31 centered at $0.645,0.858,1.640,3.792$, and $11.03 \mu \mathrm{m}$, respectively. These records also contain the surface skin temperature from meteorological reanalysis models.

\section{Description of the clear cryosphere detection algorithm}

In this section we introduce an enhancement to the detection of snow and ice within CERES FOVs and refer to it as "cryosphere rating technique." The main idea of the rating approach is to combine several indices into an aggregate quantity in such a way that each constituent of the rating either increases the rating for cryosphere pixels or decreases it for other targets. This approach requires one threshold to be established rather than a set of thresholds in traditional branching techniques.

Both snow and ice have a very distinctive spectral reflectance feature-a strong local minimum occurring at $\sim 1.6 \mu \mathrm{m}$ (see, e.g., Warren 1982, 1984). This minimum enables clear-sky snow and ice detection employing the normalized difference snow index (NDSI). The current version of the CERES SSF product does not include MODIS radiance in band $4(0.555 \mu \mathrm{m})$. It is therefore necessary to modify the definition of NDSI given in Hall et al. (1995, 2002). Fortunately, reflective properties of snow and ice are very close in MODIS bands 1 and 4; therefore, we use reflectance in MODIS band 1 rather than band 4 in our definition of NDSI:

$$
\mathrm{NDSI}_{c}=\frac{r_{1}-r_{6}}{r_{1}+r_{6}} .
$$

NDSI allows for identification of most clear-sky snow and ice targets. However, there are two other types of targets returning high values of NDSI. First, cold (ice) clouds and, second, open waters. Ice clouds usually return high NDSI for the same reason as snow and ice. One can expect that thin partly transparent ice clouds over snow and ice are the most difficult targets to be distinguished from clear-sky snow/ice.

Outside the area of specular reflection and glint, water bodies are very dark targets. TOA reflectance over clear-sky water is then dominated by the atmospheric contribution, not the surface. Thus, TOA reflectance over water bodies falls off with wavelength $\lambda$ as a combination of $\lambda^{-4}$ due to molecular scattering and $\lambda^{-a}$ due to scattering from aerosol particles, where $a$ is the aerosol Ångström exponent. This causes the reflectance in MODIS band 6 to be significantly less than that in band 1, yielding very high NDSI.

The normalized difference vegetation index (NDVI; Tucker 1979)

$$
\mathrm{NDVI}=\frac{r_{2}-r_{1}}{r_{2}+r_{1}}
$$

has high negative values over water because $r_{2}<r_{1}$ for the same reason. This enables simple discrimination between water and the cryosphere: $\mathrm{NDVI}_{\text {cryo }}>\mathrm{NDVI}_{\text {water }}$. We will see later that this inequality is met over the ROIs discussed below. We do not need to establish a threshold for NDVI separating the cryosphere and open waters within the aggregate rating approach.

The second challenging type of target is the cold ice cloud. Even though the proposed algorithm is used to compliment the CERES cloud and snow/ice recognition algorithm (Minnis et al. 2011), it does not rely on the cloud mask provided by CERES algorithm, and therefore we need a reliable tool to discriminate ice clouds from the clear-sky snow/ice. Brightness temperatures retrieved from MODIS radiances in bands 20 and 31 and the surface skin temperature, which are stored in the SSF record, can also be used for cloud discrimination. Ackerman et al. (1998) pointed out that the differences between brightness temperatures at $11 \mu \mathrm{m}, T_{31}$, and $3.9 \mu \mathrm{m}$ (bands 21/22), $T_{22}$, often reveal low-level water clouds during daylight hours. We use brightness temperature in band 20, $T_{20}$, as a replacement for $T_{22}$. It is more convenient to use a dimensionless ratio of brightness temperatures

$$
\mathrm{BTR}=T_{31} / T_{20}
$$

rather than $T_{31}-T_{20}$ in our rating approach.

We will see later that BTR may not be sensitive to cold clouds when these clouds are significantly colder than surface. For this reason, our algorithm will also use the temperature ratio

$$
\mathrm{TR}=T_{31} / T_{s},
$$

where $T_{s}$ is surface skin temperature; $T_{s}$ comes into the SSF record from meteorological reanalysis with a spatial resolution much lower than that of MODIS. Hence, it may not account for temperature variations in some situations, such as small snow-covered mountain ridges, small inland water bodies, and ocean shorelines. However the TR is a very useful tool for discrimination of 


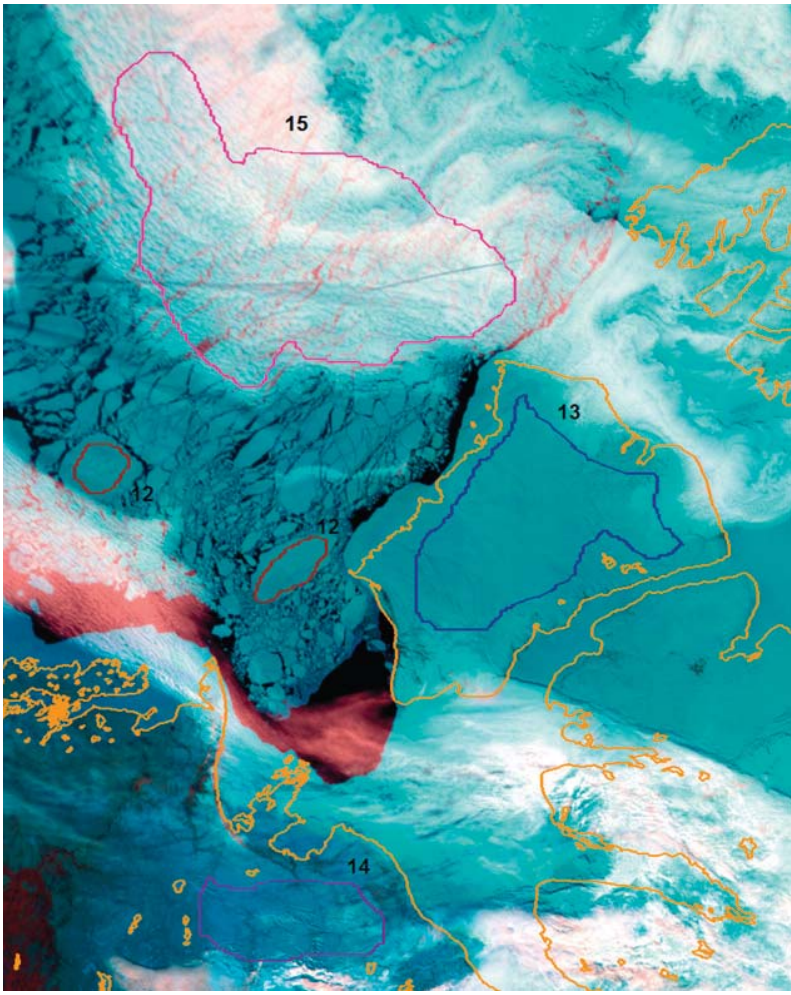

FIG. 2. A part of MODIS image MOD021km.A2004151.2000 acquired on 30 May 2004 over Canadian North, Banks Island, NWT, Canada. The same color scheme as in Fig. 1. Lambert conformal conic projection with standard parallels at $49^{\circ}$ and $77^{\circ} \mathrm{N}$ and central meridian at $95^{\circ} \mathrm{W}$. Orange contour line-coastlines, Deep blue line encloses ROI 13 from Table 1, pink line-ROI 15, violet line-ROI 14, and maroon line-ROI 12.

cold clouds that cannot be filtered out with any other available means.

The main idea of our algorithm is to produce an overall cryosphere rating (cryorating) CR that corresponds to the degree of snow/ice contamination. The $\mathrm{CR}$ is calculated as a sum of the scores generated by the individual tests:

$\mathrm{CR}=\mathrm{NDSI}_{c}+\mathrm{NDVI}+(\mathrm{TR}-1)+(\mathrm{BTR}-1)$.

Units are subtracted from TR and BTR to keep the absolute value of the rating below 1 .

The idea of an aggregated rating for cloud masking was proposed by Khlopenkov and Trishchenko (2007). They discuss in more detail the advantages of a rating approach over a branching method. One advantage is that the resulting rating can be thresholded at a certain level, giving the end user the freedom to choose the desired degree of confidence in the snow/ice contamination. Another, more important advantage is that merging all major cryosphere tests in one equation

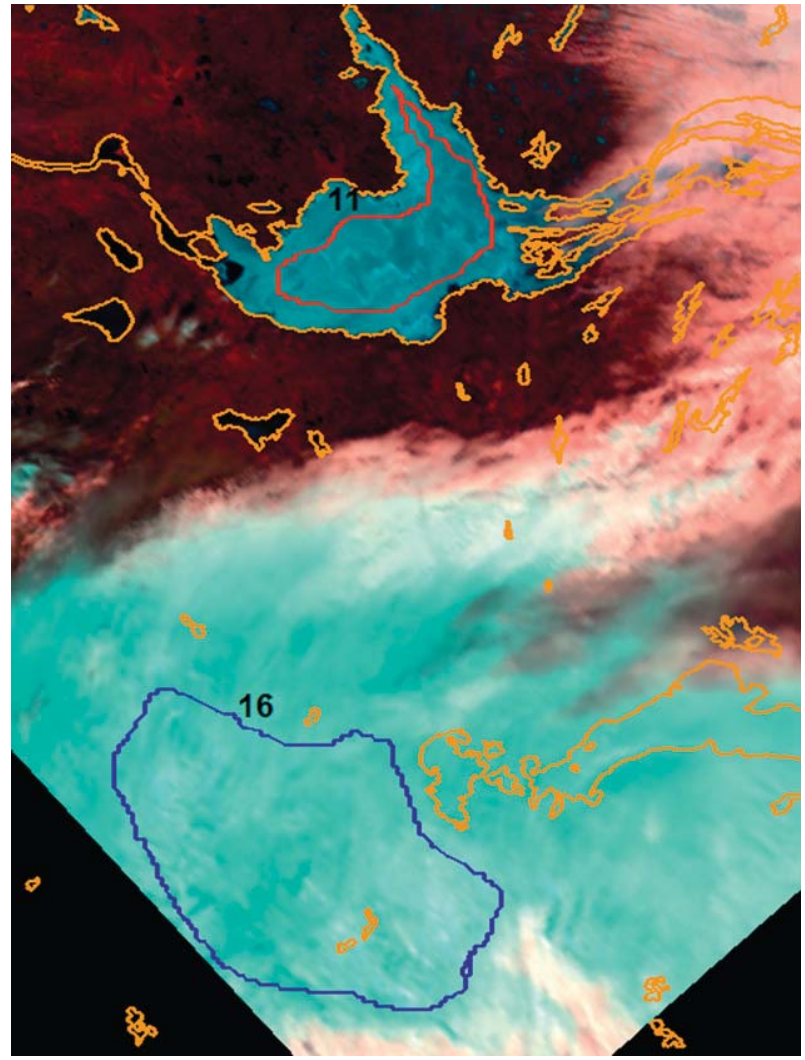

FIG. 3. Another part of the same MODIS image as in Fig. 2. Great Slave Lake, NWT, and northern parts of Alberta and Saskatchewan, Canada. Red line encloses ROI 11 from Table 1 and blue line-ROI 16.

virtually removes the possibility for one unreliable test to corrupt a whole tree of cascading branches. Thus, a combined rating dramatically increases the overall reliability of the snow/ice identification.

\section{Validation}

\section{a. Midlatitude and polar regions}

Several MODIS images acquired over North America in 2004 were selected and analyzed to reveal statistical properties of parameters constituting the cryorating over clearly identified targets. The following types of targets were considered: clear snow, clear ice, thin (translucent) cloud over ice/snow, water cloud, ice cloud, clear open water, and clear land.

Figures 2 and 3 show two parts of MODIS granule A2004151.2000 with contoured ROIs. The color scheme is the same as in Fig. 1 and gives initial scene recognition showing warm (water) clouds in white (sometimes reddish), cold (ice) clouds in light cyan, snow and ice in cyan, water in black, barely vegetated land in orange to red, and 


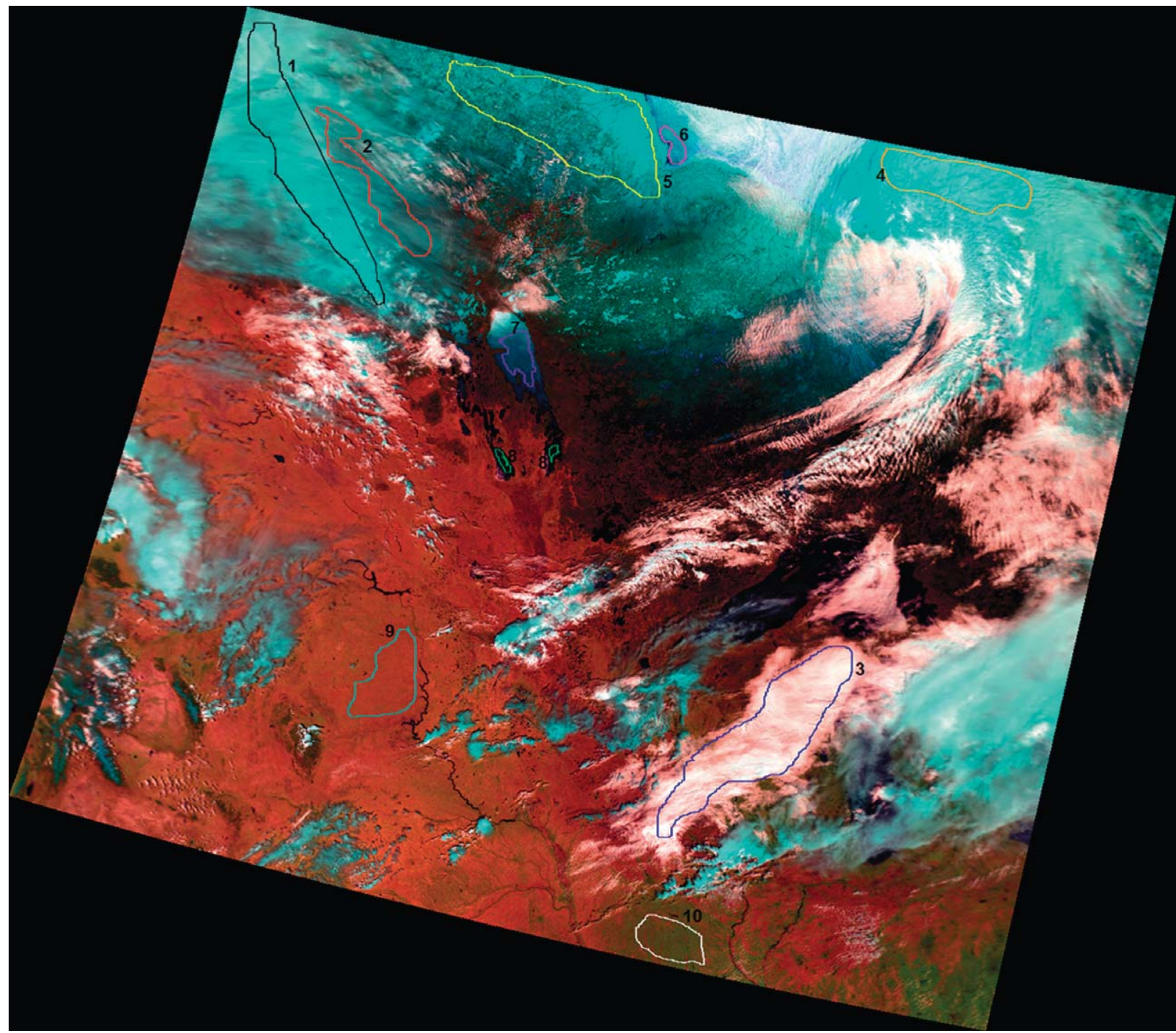

FIG. 4. MODIS image MOD021km.A2004129.1725. The same color scheme and projection as in Fig. 2. Black line encloses ROI 1, red line-ROI 2, blue line-ROI 3, orange line-ROI 4, yellow line-ROI 5, pink line-ROI 6, violet line-ROI 7, sea-green line-ROI 8 , cyan line-ROI 9, and white line-ROI 10.

vegetated land in green. Figures 4 and 5 show MODIS granules A2004129.1725 and A2004152.1550, respectively. Statistics for the CR and its constituents- the normalized difference snow and vegetation indices, NDSI and NDVI; TR; and BTR [see Eqs. (1)-(5)] —over the regions of interest contoured in Figs. 2-5 are given in Table 1. The data from the table are visualized in Figs. 6a-e.

ROIs 5, 13, and 14 represent clear-sky snow; ROIs 6 , 7, 11, and 12 represent ice; ROI 15 represents thin (partly transparent) cloud over ice; ROIs 1, 2, 4, and 16 represent cold (ice) clouds; ROI 3 represents cloud; ROIs 8 and 17 represent open water bodies; and ROIs 9 and 10 represent land. ROIs were selected by visual inspection of MODIS images. Because of the complexity of the scenes, visual selection gives only an initial point for analysis.

We see from Table 1 that the mean values of CR over snow and ice ROIs are greater than those over other targets. However, maximum values of the rating can be high over the noncryosphere, especially cold cloud ROIs. To ensure that the cryosphere rating can be used to distinguish clear-sky snow and ice from any other target, we consider the difference between mean values of $\mathrm{CR},\langle\mathrm{CR}\rangle$, and its standard deviation, $\mathrm{STD}_{\mathrm{CR}}$ :

$$
m_{c^{-}}=\langle\mathrm{CR}\rangle-2 \times \mathrm{STD}_{\mathrm{CR}}
$$




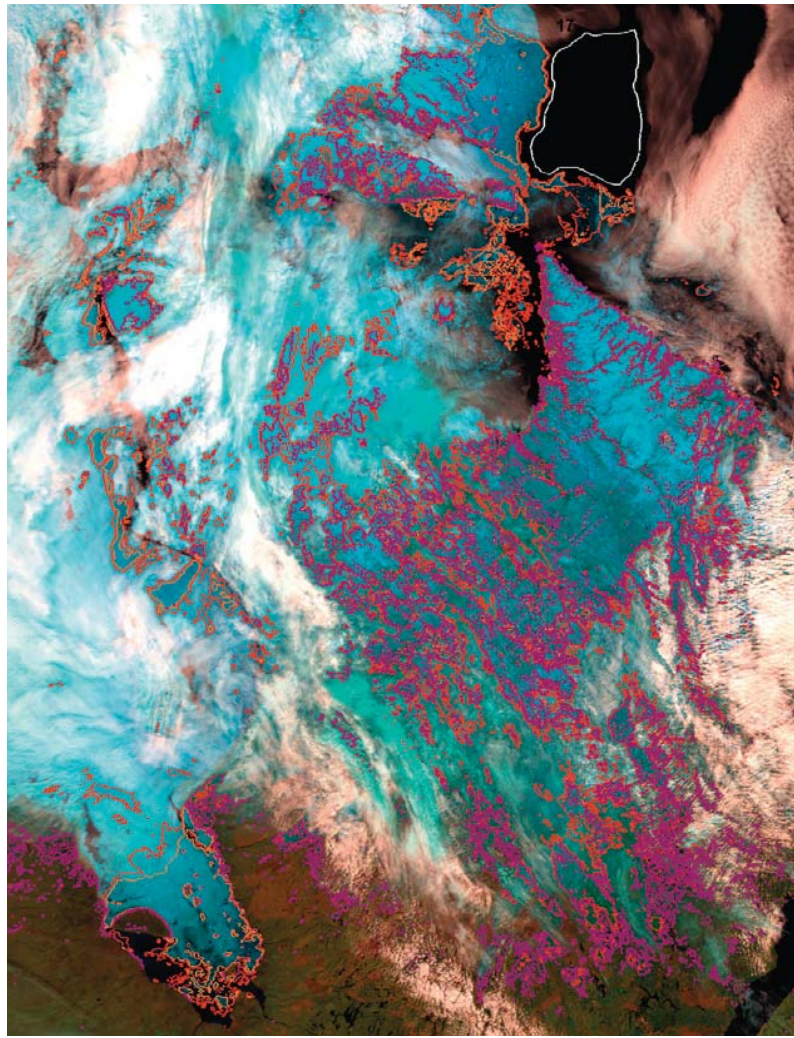

FIG. 5. MODIS image MOD021km.A2004152.1550. The same color scheme as in previous figures. Red line is a contour of $\mathrm{CR}=$ 0.55. Maroon line-MODIS instantaneous fractional snow cover (encloses all snowy pixels regardless of their snow percent coverage). Orange line-MODIS instantaneous sea ice extent. White line encloses ROI 17 from Table 1.

for snow and ice ROIs and the sum of these parameters over all other ROIs:

$$
m_{c+}=\langle\mathrm{CR}\rangle+2 \times \mathrm{STD}_{\mathrm{CR}} .
$$

Our goal is to set the cryorating threshold value such that it separates the cryosphere from the noncryosphere; that is, a value of $\mathrm{CR}$ that is greater than $m_{c+}$ for the noncryosphere and less than $m_{c-}$ for the cryosphere. If the cryorating were a normally distributed variable, then the existence of such a value would mean that the cryosphere and noncryosphere $95 \%$ confidence intervals do not overlap.

Figure $6 \mathrm{e}$ shows the cryorating score along with the standard deviation as error bars. ROI 5 returns the minimum value of $m_{c-}=0.566$ among snow/ice ROIs, ROI 14 returns a slightly greater value, $m_{c^{-}}=0.586$, and all other cryosphere ROIs (indicated as open circles) return $m_{c^{-}}>0.69$. The maximum value of $m_{c+}$ over noncryosphere ROIs is 0.524 (ROI 1), the second largest value of 0.511 is returned by ROI 4, and other noncryosphere ROIs return significantly lower values of $m_{c+}$.
Both leading values of $m_{c+}$ come from cold clouds that are the most challenging targets for snow/ice detection. They are, however, less than the minimum values of $m_{c-}$ from cryosphere ROIs, as shown in Fig. 6e. Analysis of distributions of CR within ROIs showed that the cryorating is not a normal variable, so the inequality $m_{c-}>$ $m_{c+}$ does not guarantee that the $95 \%$ confidence intervals do not overlap. We can use ROIs 1, 4, 5, and 14 as indicators of the most challenging ROIs and then examine the actual distributions of CR over these ROIs in detail to make sure that cryorating reliably separates clear-sky cryosphere from ice clouds; $95 \%$ of the pixels in ROI 1 and 4 have a CR value less than 0.457 and 0.479 , respectively, and $95 \%$ of the pixels in ROI 5 and 14 have a CR value greater than 0.587 and 0.570 , respectively. Thus, the cryorating separates clear-sky snow and ice from any other scene with at least $95 \%$ confidence.

We see from Figs. 6a-d that none of the indices constituting the cryorating can separate the clear cryosphere from other targets. Application of fixed thresholds leads to a great chance of erroneous scene identification. Assume that we use a set thresholds indicating cryosphere, like NDSI $>0.4$, NDVI $>-0.15$, BTR $>0.92$, and TR $>$ 0.95 . Then only ROIs $3,8,9,10$, and 17 do not pass the first two checks completely. The third check removes ROI 15. Only the last check discards ROIs 1, 2, 4, and 16. As a result, this series of checks gives ROIs 5, 6, 7, and 11-14 as cryosphere. Figures $6 \mathrm{a}-\mathrm{c}$, however, show that there does not exist a set of thresholds for NDSI NDVI, and BTR reliably separating cold clouds and snow, while analysis of these quantities over ROIs 1,2, and 5 shows that a sum of them is a somewhat reliable measure of presence of clear snow. However, cold clouds and snow can be distinguished by taking TR into consideration despite the disadvantage discussed above. These results and Fig. 6e clearly indicate that the cryorating enables reliable detection of cryosphere scenes with a single test.

\section{b. Temperature inversions}

All cloud ROIs considered above have a mean TR below 1 . Temperature inversions may impose a challenge to the proposed approach of distinguishing snow and ice from clouds because the cloud-top temperature is greater than the surface temperature, making TR $>1$ and thus increasing the overall rating over such clouds. The temperature difference across inversions can be up to $14.3^{\circ} \mathrm{C}$ with surface temperature $-37.4^{\circ} \mathrm{C}$ (Bradley et al. 1992), yielding $\mathrm{TR}=1.061$. However, this high temperature difference takes place during polar night. More realistic estimates of the TR under daytime inversion conditions can be made using data from Fairbanks, Alaska (Bourne et al. 2010), in February. Assuming 
TABLE 1. Statistics of the cryorating and its constituents over the selected ROIs.

\begin{tabular}{|c|c|c|c|c|c|}
\hline $\begin{array}{l}\text { MODIS granule, ROI number, brief description, } \\
\text { number of pixels within ROI }\end{array}$ & Parameter & Mean value & Std dev & Min value & Max value \\
\hline A2004129.1725 & CR & 0.336 & 0.094 & 0.041 & 0.546 \\
\hline ROI 1 & NDSI & 0.529 & 0.066 & 0.304 & 0.663 \\
\hline Cold cloud & NDVI & 0.046 & 0.007 & 0.027 & 0.062 \\
\hline \multirow[t]{2}{*}{62421 pixels } & TR & 0.860 & 0.017 & 0.813 & 0.916 \\
\hline & BTR & 0.901 & 0.023 & 0.815 & 0.955 \\
\hline A2004129.1725 & $\mathrm{CR}$ & 0.319 & 0.061 & 0.015 & 0.449 \\
\hline ROI 2 & NDSI & 0.477 & 0.046 & 0.227 & 0.572 \\
\hline Thin cold cloud & NDVI & 0.051 & 0.007 & 0.036 & 0.087 \\
\hline \multirow[t]{2}{*}{23092 pixels } & TR & 0.874 & 0.018 & 0.824 & 0.915 \\
\hline & BTR & 0.917 & 0.017 & 0.848 & 0.948 \\
\hline A2004129.1725 & $\mathrm{CR}$ & -0.016 & 0.058 & -0.211 & 0.158 \\
\hline ROI 3 & NDSI & 0.058 & 0.057 & -0.263 & 0.225 \\
\hline Cloud & NDVI & 0.050 & 0.015 & 0.009 & 0.409 \\
\hline \multirow[t]{2}{*}{70476 pixels } & TR & 0.965 & 0.012 & 0.893 & 0.986 \\
\hline & BTR & 0.911 & 0.013 & 0.829 & 0.960 \\
\hline A2004129.1725 & $\mathrm{CR}$ & 0.381 & 0.065 & 0.144 & 0.613 \\
\hline ROI 4 & NDSI & 0.561 & 0.038 & 0.417 & 0.711 \\
\hline Cold cloud & NDVI & 0.032 & 0.005 & 0.011 & 0.049 \\
\hline \multirow[t]{2}{*}{33110 pixels } & TR & 0.887 & 0.014 & 0.844 & 0.942 \\
\hline & BTR & 0.900 & 0.018 & 0.822 & 0.948 \\
\hline A2004129.1725 & $\mathrm{CR}$ & 0.734 & 0.084 & -0.072 & 0.818 \\
\hline ROI 5 & NDSI & 0.729 & 0.079 & 0.085 & 0.842 \\
\hline Snow, Hudson Bay shore & NDVI & 0.041 & 0.021 & -0.022 & 0.160 \\
\hline \multirow{2}{*}{79682 pixels } & TR & 0.993 & 0.009 & 0.928 & 1.014 \\
\hline & BTR & 0.971 & 0.014 & 0.825 & 0.980 \\
\hline A2004129.1725 & $\mathrm{CR}$ & 0.781 & 0.045 & 0.393 & 0.826 \\
\hline ROI 6 & NDSI & 0.830 & 0.034 & 0.562 & 0.904 \\
\hline Sea ice, Hudson Bay & NDVI & -0.020 & 0.013 & -0.072 & 0.006 \\
\hline \multirow[t]{2}{*}{5138 pixels } & TR & 1.001 & 0.002 & 0.984 & 1.008 \\
\hline & BTR & 0.971 & 0.012 & 0.876 & 0.979 \\
\hline A2004129.1725 & $\mathrm{CR}$ & 0.788 & 0.049 & 0.478 & 0.847 \\
\hline ROI 7 & NDSI & 0.892 & 0.071 & 0.464 & 0.958 \\
\hline Ice, Lake Winnipeg & NDVI & -0.052 & 0.028 & -0.140 & 0.058 \\
\hline \multirow[t]{2}{*}{6475 pixels } & TR & 0.969 & 0.003 & 0.962 & 0.979 \\
\hline & BTR & 0.980 & 0.002 & 0.962 & 0.984 \\
\hline A2004129.1725 & $\mathrm{CR}$ & 0.271 & 0.053 & -0.127 & 0.608 \\
\hline ROI 8 & NDSI & 0.897 & 0.061 & -0.039 & 0.944 \\
\hline Open water & NDVI & -0.564 & 0.067 & -0.628 & -0.039 \\
\hline Lake Winnipeg and Lake Manitoba & TR & 0.949 & 0.004 & 0.941 & 0.977 \\
\hline 1403 pixels & BTR & 0.989 & 0.002 & 0.961 & 0.991 \\
\hline A2004129.1725 & $\mathrm{CR}$ & -0.129 & 0.029 & -0.239 & 0.086 \\
\hline ROI 9 & NDSI & -0.435 & 0.020 & -0.502 & -0.339 \\
\hline Land & NDVI & 0.310 & 0.032 & 0.201 & 0.568 \\
\hline North Dakota and South Dakota & TR & 1.029 & 0.013 & 0.994 & 1.055 \\
\hline 34255 pixels & BTR & 0.966 & 0.002 & 0.957 & 0.973 \\
\hline A2004129.1725 & $\mathrm{CR}$ & 0.068 & 0.058 & -0.240 & 0.177 \\
\hline ROI 10 & NDSI & -0.513 & 0.034 & -0.564 & -0.209 \\
\hline Land & NDVI & 0.614 & 0.077 & 0.280 & 0.757 \\
\hline Iowa, Illinois, Missouri & $\mathrm{TR}$ & 0.996 & 0.005 & 0.978 & 1.017 \\
\hline 28147 pixels & BTR & 0.971 & 0.005 & 0.945 & 0.980 \\
\hline A2004151.2000 & $\mathrm{CR}$ & 0.828 & 0.018 & 0.690 & 0.858 \\
\hline ROI 11 & NDSI & 0.890 & 0.014 & 0.741 & 0.923 \\
\hline Ice & NDVI & -0.004 & 0.006 & -0.065 & 0.009 \\
\hline Great Slave Lake & TR & 0.961 & 0.003 & 0.941 & 0.970 \\
\hline 7785 pixels & BTR & 0.981 & 0.004 & 0.950 & 0.986 \\
\hline
\end{tabular}


TABLE 1. (Continued)

\begin{tabular}{|c|c|c|c|c|c|}
\hline $\begin{array}{l}\text { MODIS granule, ROI number, brief description, } \\
\text { number of pixels within ROI }\end{array}$ & Parameter & Mean value & Std dev & Min value & Max value \\
\hline A2004151.2000 & $\mathrm{CR}$ & 0.788 & 0.030 & 0.726 & 0.847 \\
\hline ROI 12 & NDSI & 0.830 & 0.022 & 0.784 & 0.897 \\
\hline Sea ice & NDVI & -0.003 & 0.005 & -0.044 & 0.009 \\
\hline Beaufort Sea & TR & 0.985 & 0.006 & 0.975 & 0.994 \\
\hline 4520 pixels & BTR & 0.976 & 0.004 & 0.968 & 0.982 \\
\hline A2004151.2000 & CR & 0.797 & 0.040 & 0.428 & 0.848 \\
\hline ROI 13 & NDSI & 0.842 & 0.033 & 0.549 & 0.887 \\
\hline Snow & NDVI & -0.002 & 0.004 & -0.016 & 0.015 \\
\hline Banks Island & TR & 0.981 & 0.003 & 0.964 & 0.994 \\
\hline 31492 pixels & BTR & 0.977 & 0.009 & 0.892 & 0.984 \\
\hline A2004151.2000 & $\mathrm{CR}$ & 0.768 & 0.091 & 0.209 & 0.875 \\
\hline ROI 14 & NDSI & 0.861 & 0.083 & 0.320 & 0.953 \\
\hline Snow & NDVI & -0.048 & 0.010 & -0.078 & 0.001 \\
\hline NWT & TR & 0.990 & 0.011 & 0.955 & 1.018 \\
\hline 12641 pixels & BTR & 0.966 & 0.019 & 0.887 & 0.985 \\
\hline A2004151.2000 & $\mathrm{CR}$ & 0.253 & 0.052 & 0.024 & 0.523 \\
\hline ROI 15 & NDSI & 0.282 & 0.055 & 0.035 & 0.559 \\
\hline Thin cloud over ice, & NDVI & 0.010 & 0.006 & -0.035 & 0.031 \\
\hline Beaufort Sea & TR & 0.961 & 0.004 & 0.937 & 0.970 \\
\hline 73693 pixels & BTR & 0.891 & 0.006 & 0.863 & 0.919 \\
\hline A2004151.2000 & $\mathrm{CR}$ & 0.253 & 0.089 & 0.008 & 0.528 \\
\hline ROI 16 & NDSI & 0.486 & 0.048 & 0.332 & 0.643 \\
\hline Ice cloud & NDVI & 0.050 & 0.004 & 0.029 & 0.068 \\
\hline \multirow[t]{2}{*}{32265 pixels } & TR & 0.835 & 0.025 & 0.785 & 0.913 \\
\hline & BTR & 0.881 & 0.027 & 0.805 & 0.954 \\
\hline 2004152.1550 & $\mathrm{CR}$ & 0.218 & 0.035 & -0.071 & 0.409 \\
\hline ROI 17 & NDSI & 0.543 & 0.061 & 0.052 & 0.794 \\
\hline Open water, & NDVI & -0.301 & 0.030 & -0.422 & -0.067 \\
\hline Labrador sea & TR & 0.993 & 0.002 & 0.986 & 0.998 \\
\hline 34121 pixels & BTR & 0.983 & 0.002 & 0.958 & 0.990 \\
\hline
\end{tabular}

a temperature difference of $9^{\circ} \mathrm{C}$ and the surface temperature of $-19^{\circ} \mathrm{C}$ [see Figs. 3a and 3b in Bourne et al. (2010)] yields $\mathrm{TR}=1.035$. Assuming also that $\mathrm{TR}=1$ for clouds, we conclude that an inversion may increase $m_{c+}$ for ice clouds up to 0.558 . However, it seems unlikely to observe ice clouds under the cap of inversions.

Several MODIS images acquired in winter 2004 over Alaska and the Yukon Territory were examined to find inversion clouds with high NDSI but such conditions were not found. A temperature inversion cloud ROI was selected in MODIS granule A2004046.2010 (15 February 2004) as a typical example to demonstrate the behavior of the cryosphere rating parameters. The ROI is in the Yukon Territory and the Northwest Territories (NWT), Canada, centered at approximately $65.5^{\circ} \mathrm{N}, 132.6^{\circ} \mathrm{W}$ and includes 4336 pixels. The ROI returns the following values of parameters, constituting $\mathrm{CR}$ [mean value (standard deviation)]: TR-1.027 (0.003), BTR-0.913 (0.007), NDSI-0.362 (0.041), NDVI-0.052 (0.012), and $\mathrm{CR}-0.354$ (0.037) with the maximum value of 0.547 . Thus, clouds formed in temperature inversions can be discriminated from snow and ice using the cryorating approach.

\section{c. Thresholding cryorating}

To decide whether a pixel is a clear-sky snow/ice scene, we need to establish a threshold for the CR, where pixels returning $\mathrm{CR}$ values over the threshold are considered clear-sky cryosphere. Taking into consideration that the purpose of the algorithm is the selection of CERES FOVs to update the surface albedo history map over the cryosphere, after examination of numerous MODIS images, a threshold of $\mathrm{CR}_{c}=0.55$ was established. Figure 5 shows red contour line $\mathrm{CR}=0.55$ on top of a MODIS image along with MODIS fractional snow extent (MOD10_L2) and sea ice extent (MOD29). Snow and ice extent obtained with the cryorating approach coincides very well with these MODIS products. There are only two remarkable differences between the MODIS products and the cryorating approach. First is the edge of snow extent over land (e.g., south to Hudson Bay) where MOD10_L2 returns low fraction (below 
(a)

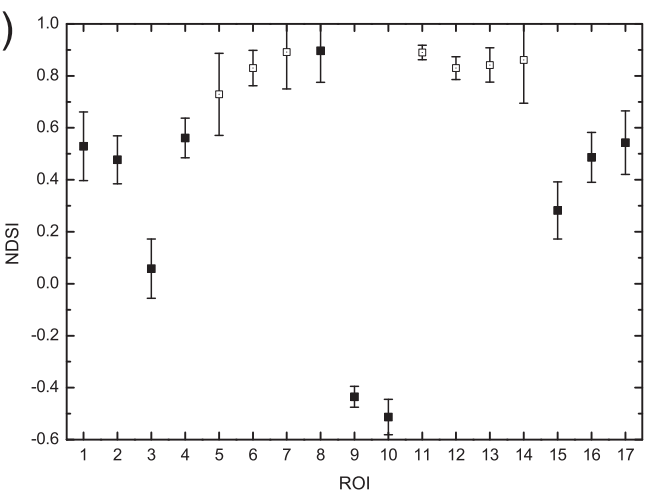

(c)

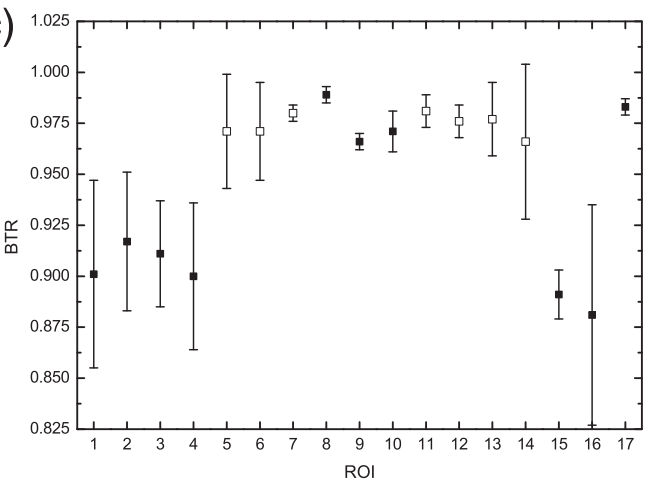

(e)

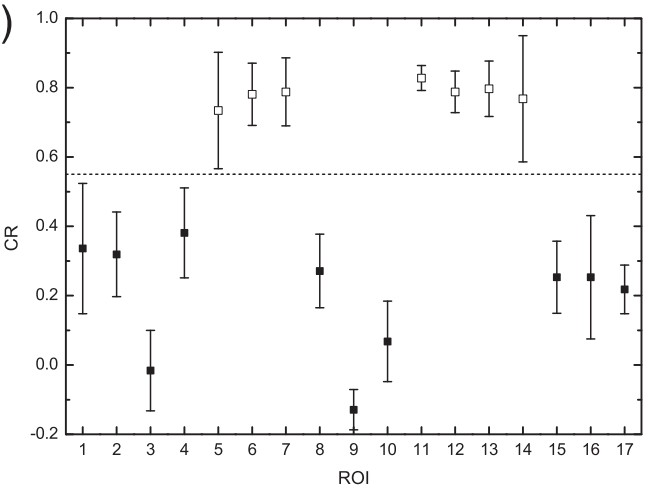

(b)

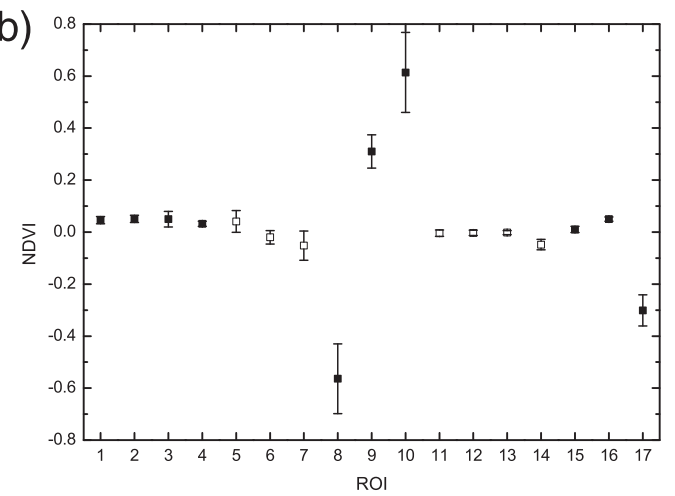

(d)

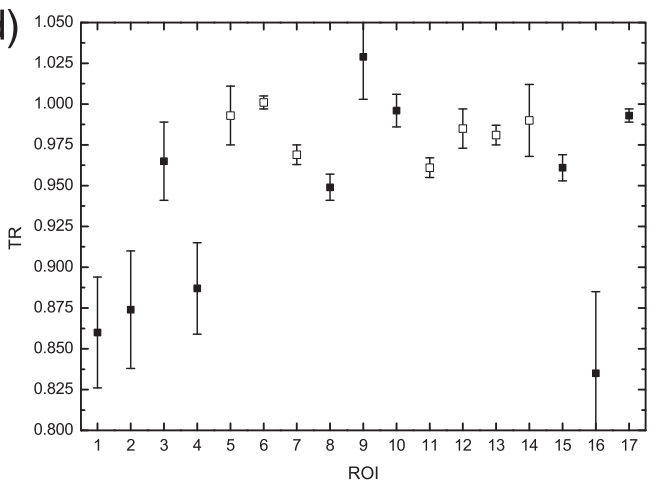

FIG. 6. Cryorating and its components for the regions listed in Table 1 as a function of region number. Error bars indicate two standard deviations. Filled squares are noncryospehre regions, and empty squares are cryosphere regions. (a) NDSI, (b) NDVI, (c) BTR, (d) TR, and (e) CR. Dashed horizontal line indicates the threshold value (0.55) separating the cryosphere from the noncryosphere.
$30 \%$ ) of snow. However, the presence of snow in some of these locations is questionable. Second, it shows a slightly wider sea ice extent over James Bay. The area looks clear where $\mathrm{CR}>0.55$, but MOD29 returns cloud instead of sea ice flag.

Going back to Fig. 1 and the erroneously identified CERES FOV, we can now evaluate CR for MODIS pixels within the ROI circled in Fig. 1. The CR varies from -0.065 to 0.701 over this ROI with the mean value of 0.383 and a STD of $0.141 ; 86.7 \%$ of the pixels in this ROI have a CR less than 0.55 . CR calculated from values stored in the SSF product for this FOV is 0.389. Thus, this FOV, using the new CR, would be excluded from use as a clearsky footprint and not be used in determining a surface albedo for the SARB surface albedo history map.

\section{d. Spurious snow detection}

The authors of the MODIS snow detection algorithm pointed out (Hall et al. 2002) that NDSI-based snow recognition may return spurious snow identification over regions known not to have snow, such as dark forests in equatorial zones. Several MODIS images over Africa and South America have been analyzed to check if the cryorating is high enough to produce false snow recognition. It was found that the problem exists over five types of targets: very bright cold clouds, very dark inland waters, wild fire plumes over water (especially off the South America coast), salt flats (e.g., Salar de Uyuni, Bolivia) and some minor parts of wadis in deserts (e.g., Wadi Howar, at $\sim 15.70^{\circ} \mathrm{N}, 23.10^{\circ} \mathrm{E}$ ). All these types of 
targets return a high cryorating only at sparse pixels that do not form continuous areas. Taking into account that this algorithm is to be used for MODIS radiances averaged over CERES FOVs, sparse occurrence of false snow over MODIS images reduces the risk of the error of commission. However, this algorithm can be used independently as an alternative snow and ice mapping tool for MODIS after minor modifications. These modifications may differ from the pure aggregate rating approach by establishing a mixed rating and branching scheme. For example, most false snow identification over dark waters can be removed with the condition $r_{6 \mathrm{cs}}>0.01$, while bright cold clouds are eliminated with the condition $r_{6 \mathrm{cs}}<0.2$. All other challenging targets can be discriminated with condition $T_{31}<277 \mathrm{~K}$ as proposed by Hall et al. (2001).

\section{Conclusions}

A new scene identification algorithm is proposed for clear-sky snow and ice identification. The algorithm is designed to be used in the processing of CERES data as an additional (with respect to the CERES production chain) filter, ensuring daytime scene identification. The algorithm does not use any cloud mask as an input, only the spectral radiances in five MODIS bands stored in the CERES SSF product. The only additional input data used in the proposed algorithm are the surface skin temperature from the GEOS-4(GEOS-5) reanalysis that is also a part of the CERES SSF record. The algorithm was tuned to work most efficiently over midlatitude and polar regions.

The algorithm can be used as an independent snow and ice masking tool for MODIS [or other sensors providing similar spectral information, e.g., Visible Infrared Imaging Radiometer Suite (VIIRS)] with suggested minor modifications such as limits on reflectance at $1.6 \mu \mathrm{m}$ and brightness temperature at $11 \mu \mathrm{m}$.

A distinctive feature of the algorithm is the aggregated cryosphere rating that combines four variables designed to highlight snow and ice more than targets of any other type. The cryorating is a measure of confidence of snow/ice contamination of a pixel. It is shown that the cryorating provides all the necessary information for identification of clear-sky snow and ice. The variables constituting the cryosphere rating are the normalized difference snow index, the normalized difference vegetation index, the ratio of brightness temperatures at 11 and $3.7 \mu \mathrm{m}$, and the ratio of brightness temperature at $11 \mu \mathrm{m}$ and surface skin temperature.

The major difference from other cryosphere recognition algorithms is that the combined rating algorithm is not based on a branching methodology. The advantage is that the aggregated rating approach requires setting a single threshold compared to finding several empirical thresholds for each individual test. A single error in a sequence of tests with empirical thresholds can spoil or even invert the final decision. The statistical error of the aggregated rating is much smaller than the sum of errors of each test that it combines. Thus, the aggregated rating is much more reliable than a cascading sequence of tests. Also, the aggregated rating allows for a simple adjustment to the final threshold, depending on how strict the end user's operational requirements are on the scene recognition.

Snow and sea ice extent obtained with the rating algorithm was compared against instantaneous MODIS snow and sea ice products. It was shown that the snow extent coincides very well except for the pixels with relatively low fraction of snow and cloud edges. The sea ice extent also shows a good agreement with the MODIS sea ice extent, except for the areas covered by very thin transparent clouds. Overall, the presented analysis has demonstrated the high potential of our algorithm in recognition of the snow/ice scenes, which can be a beneficial supplement to the standard CERES algorithm.

Acknowledgments. CERES data are supplied by the NASA Langley Research Center Atmospheric Science Data Center. MODIS level 1 atmosphere and land data products data are supplied by the NASA Goddard Distributed Active Archive Center. MODIS snow and ice products are supplied by the National Snow and Ice Data Center.

\section{REFERENCES}

Ackerman, S. A., K. I. Strabala, W. P. Menzel, R. A. Frey, C. C. Moeller, and L. E. Gumley, 1998: Discriminating clear sky from clouds with MODIS. J. Geophys. Res., 103 (D24), 32 141-32 157.

Bloom, S., and Coauthors, 2005: Documentation and validation of the Goddard Earth Observing System (GEOS) Data Assimilation System - Version 4. Technical Report Series on Global Modeling and Data Assimilation, Vol. 26, NASA/TM-20051046060, $165 \mathrm{pp}$.

Bourne, S. M., U. S. Bhatt, J. Zhang, and R. Thoman, 2010: Surfacebased temperature inversions in Alaska from a climate perspective. Atmos. Res., 95, 353-366.

Bradley, R. S., F. T. Keimig, and H. F. Diaz, 1992: Climatology of surface-based inversions in the North American Arctic. J. Geophys. Res., 97 (D14), 15 699-15 712.

Caldwell, T. E., and Coauthors, 2008: Clouds and the Earth's Radiant Energy System (CERES) Data Management System Data Products Catalog, release 4, version 16. NASA, 240 pp. [Available online at http://eosweb.larc.nasa.gov/PRODOCS/ ceres/DPC/.]

Charlock, T. P., and Coauthors, 1997: Clouds and the Earth's Radiant Energy System (CERES) Algorithm Theoretical Basis Document: Compute surface and atmospheric fluxes (subsystem 5.0). 
NASA CERES ATBD, Release 2.2, 84 pp. [Available online at http://science.larc.nasa.gov/ceres/ATBD/.]

— , F. G. Rose, D. A. Rutan, Z. Jin, and S. Kato, 2006: The global surface and atmosphere radiation budget: An assessment of accuracy with 5 years of calculations and observations. Preprints, 12th Conf. on Atmospheric Radiation, Madison, WI, Amer. Meteor. Soc., 10.5. [Available online at https://ams.confex.com/ ams/Madison2006/techprogram/paper_112984.htm.]

Fu, Q., and K. N. Liou, 1993: Parameterization of radiative properties of cirrus clouds. J. Atmos. Sci., 50, 2008-2025.

Hall, D. K., G. A. Riggs, and V. V. Salomonson, 1995: Development of methods for mapping global snow cover using Moderate Resolution Imaging Spectroradiometer (MODIS) data. Remote Sens. Environ., 54, 127-140.

— - _ and - 2001: Algorithm Theoretical Basis Document (ATBD) for the MODIS snow and sea ice-mapping algorithms. NASA, 45 pp. [Available online at http://modis-snow-ice.gsfc. nasa.gov $/$ ? $=$ atbd\& $\mathrm{t}=$ atbd.]

,,,--- N. E. DiGirolamo, and K. J. Bayr, 2002: MODIS snow-cover products. Remote Sens. Environ., 83, 181-194.

_ J. R. Key, K. A. Casey, G. A. Riggs, and D. J. Cavalieri, 2004: Sea ice surface temperature product from MODIS. IEEE Trans. Geosci. Remote Sens., 42, 1076-1087.

Kato, S., F. G. Rose, and T. P. Charlock, 2005: Computation of domain-averaged irradiance using satellite-derived cloud properties. J. Atmos. Oceanic Technol., 22, 146-164.

—, N. G. Loeb, P. Minnis, J. A. Francis, T. P. Charlock, D. A. Rutan, E. E. Clothiaux, and S. Sun-Mack, 2006: Seasonal and interannual variations of top-of-atmosphere irradiance and cloud cover over polar regions derived from the CERES data set. Geophys. Res. Lett., 33, L19804, doi:10.1029/2006gl026685.

Khlopenkov, K. V., and A. P. Trishchenko, 2007: SPARC: New cloud, snow, and cloud shadow detection scheme for historical AVHRR data over Canada. J. Atmos. Oceanic Technol., 24, 322-343.

Loeb, N. G., S. Kato, K. Loukachine, and N. Manalo-Smith, 2005: Angular distribution models for top-of-atmosphere radiative flux estimation from the Clouds and the Earth's Radiant Energy System instrument on the Terra satellite. Part I: Methodology. J. Atmos. Oceanic Technol., 22, 338-351.

,,,--- , and D. R. Doelling, 2007: Angular distribution models for top-of-atmosphere radiative flux estimation from the Clouds and the Earth's Radiant Energy System instrument on the Terra satellite. Part II: Validation. J. Atmos. Oceanic Technol., 22, 338-351.

Minnis, P., D. F. Young, S. Sun-Mack, P. W. Heck, D. R. Doelling, and Q. Trepte, 2003: CERES cloud property retrievals from imagers on TRMM, Terra, and Aqua. Remote Sensing of Clouds and the Atmosphere VIII, K. P. Schaefer et al., Eds., International Society for Optical Engineering (SPIE Proceedings, Vol. 5235), doi:10.1117/12.511210.
_ O. Z. Trepte, Y. Chen, R. R. Brown, S. L. Gibson, and P. W. Heck, 2004: Diurnal, seasonal, and interannual variations of cloud properties derived for CERES from imager data. Preprints, 13 th Conf. on Satellite Meteorology and Oceanography, Norfolk, VA, P6.10. [Available online at https:// ams.confex.com/ams/13SATMET/techprogram/paper_79349. htm.]

- - and Coauthors, 2008: Cloud detection in nonpolar regions for CERES using TRMM VIRS and Terra and Aqua MODIS data. IEEE Trans. Geosci. Remote Sens., 46, 3857-3884.

— , and Coauthors, 2011: CERES edition-2 cloud property retrievals using TRMM VIRS and Terra and Aqua MODIS data-Part I: Algorithms. IEEE Trans. Geosci. Remote Sens., 49, 4374-4400.

Rienecker, M. M., and Coauthors, 2008: The GEOS-5 Data Assimilation System-Documentation of versions 5.0.1, 5.1.0, and 5.2.0. Technical Report Series on Global Modeling and Data Assimilation, Vol. 27, NASA/TM-2008-104606, 101 pp.

Rose, F. G., and T. P. Charlock, 2002: New Fu-Liou code tested with ARM Raman lidar and CERES in pre-CALIPSO sensitivity study. Preprints, 11th Conf. on Atmospheric Radiation, Ogden, UT, Amer. Meteor. Soc., P4.8. [Available online at https://ams.confex.com/ams/11AR11CP/techprogram/paper_ 42757.htm.]

Rutan, D., F. Rose, M. Roman, N. Manalo-Smith, C. Schaaf, and T. Charlock, 2009: Development and assessment of broadband surface albedo from Clouds and the Earth's Radiant Energy System clouds and radiation swath data product. J. Geophys. Res., 114, D08125, doi:10.1029/2008JD010669.

Schaaf, C. B., and Coauthors, 2002: First operational BRDF, albedo and nadir reflectance products from MODIS. Remote Sens. Environ., 83, 135-148.

Trepte, Q., P. Minnis, and R. F. Ardoini, 2002: Daytime and nighttime polar cloud and snow identification using MODIS data. Optical Remote Sensing of the Atmosphere and Clouds III, H.-L. Huang, D. Lu, and Y. Sasano, Eds., International Society for Optical Engineering (SPIE Proceedings, Vol. 4891), doi:10.1117/12.467306.

Tucker, C. J., 1979: Red and photographic infrared linear combinations for monitoring vegetation. Remote Sens. Environ., 8, 127-150.

Warren, S. G., 1982: Optical properties of snow. Rev. Geophys. Space Phys., 20, 67-89.

_ 1984: Optical constants of ice from the ultraviolet to the microwave. Appl. Opt., 23, 1206-1225.

Wielicki, B. A., B. R. Barkstrom, E. F. Harrison, R. B. Lee III, G. L. Smith, and J. E. Cooper, 1996: Clouds and the Earth's Radiant Energy System (CERES): An Earth Observing System experiment. Bull. Amer. Meteor. Soc., 77, 853-868. 